\title{
Biotiitin käyttökelpoisuus perunanviljelyssä
}

\author{
Kristian Forsman $^{1)}$, Elina Virtanen ${ }^{1)}$ ja Janne Pulkkinen ${ }^{2)}$ \\ ${ }^{1)}$ MTT Pohjois-Pohjanmaan tutkimusasema,92400 Ruukki, etunimi.sukunmi@mtt.fi \\ ${ }^{2)}$ Kemira GrowHow Oyj, 00181 Helsinki, janne.pulkkinen@kemira-growhow.com
}

\section{Tiivistelmä}

Biotiittia saadaan Kemira GrowHow'n Siilinjärven lannoitetehtaalta. Kemira-Biotiittina myytävä maanparannusaine sisältää kaliumia $5 \%$, kalsiumia $7 \%$ ja magnesiumia $10 \%$. Biotiitin vaikutusta perunamaalla on seurattu MTT:n Pohjois-Pohjanmaan tutkimusaseman toimesta vuodesta 2002.

Biotiitin sisältämä kalsium on suurelta osin kalkkia, joten biotiitilla on maata neutraloivaa vaikutusta. Biotiitin kalkitusvaikutus on kuitenkin vaatimaton. Kevään 2002 biotiittilisä 10 t/ha nosti maan pH:ta kahden ensimmäisen seurantavuoden aikana vain $0,2 \mathrm{pH}$-yksikköä $(\mathrm{p}<0,10)$ verrattuna muutokseen käsittelemättömässä koejäsenessä. Perunan kannalta tämä on merkityksellistä sen vuoksi, että happamuus on yksi suurimmista perunaruven viihtyvyyteen vaikuttavista tekijöistä maassa, joten vähäinen $\mathrm{pH}$ vaikutus ei johda kohtuuttomaan rupiriskin lisääntymiseen.

Biotiittilisä nosti maan kalsiumpitoisuutta erittäin selvästi $(\mathrm{p}<0,05)$. Ensimmäisenä vuonna maan kalsiumluvut nousivat lähes $140 \mathrm{mg} / \mathrm{l}$ ja toisena vuonna noin $50 \mathrm{mg} / \mathrm{l}$. Kalsium huuhtoutuu melko herkästi karkeilta mailta talvien aikana, mutta biotiitin vaikutus maan kalsiumlukuihin oli tilastollisesti merkitsevä vielä vuoden 2005 keväällä. Biotiitilla pystytään korvaamaan yleisessä käytössä oleva kalsiumin erillislannoitus ainakin kahden vuoden ajan.

Kaliumin osalta ensimmäisenä kasvukautena ei juurikaan tapahtunut muutoksia viljavuusluvuissa. Toisena kasvukautena ero biotiitilla käsitellyn ja käsittelemättömän koejäsenen välillä nousi selvästi $(\mathrm{p}<0,05)$. Kasvukauden 2004 jälkeen biotiitin kaliumvaikutus alkoi vähetä. Biotiitin kalium ei yleensä huuhtoudu herkästi, mutta kasvukauden 2004 erittäin kosteat olosuhteet uuttoivat todennäköisesti tehokkaasti myös biotiitin kaliumia. Perunamaat ovat tyypillisesti karkeita maita, joiden liukoinen kaliumpitoisuus on alhainen ja lisäksi reservikaliuminkin määrä saattaa olla moniin muihin maihin verrattuna hyvin alhainen. Peruna suurena kaliumin käyttäjänä hyötyy maan korkeasta kaliumtasosta.

Vaikka biotiitti sisältää ravinteista eniten magnesiumia, sen vaikutus on hyvin pieni. Seurannan aikana biotiitin mukana tulleesta 1000 kilon magnesiumlisästä on vapautunut vain joitain kymmeniä kiloja. Käytännössä tämä tarkoittaa, biotiitin käyttö magnesiumvoittoisilla perunamailla on turvallista eikä se vääristä ravinnesuhteita.

Biotiitin ravinteiden liukoisuutta voidaan happokäsittelyllä parantaa. Tällöin biotiitista saadaan vapautumaan myös suuria määriä magnesiumia $(\mathrm{p}<0,001)$. Lisäksi kalsium- ja erityisesti kaliumvaikutus tehostuu ravinteiden liukenemisen tapahtuessa aikaisemmassa vaiheessa viljelykiertoa, mutta näiden ravinteiden kokonaisvapautumiseen ei happokäsittelyllä kuitenkaan ollut havaintojen perusteella oleellista vaikutusta.

\section{Asiasanat:}

biotiitti, maanparannus, kalkitus, lannoitus, kalium, kalsium, magnesium, $\mathrm{pH}$, peruna 


\section{Johdanto}

Biotiitti on kiillemineraali, jota saadaan talteen Kemira GrowHow’n Siilinjärven tehtailta apatiittimalmin louhinnan ja rikastuksen yhteydessä. Sitä hyödynnetään lannoitetuotannossa sekä myydään sellaisenaan maanparannukseen, ensisijaisesti hidasvaikutteiseksi kaliumlannoitteeksi kauppanimellä Kemira-Biotiitti. Kemira-Biotiitti sisältää myös kalsiittia, joten tuotteella on kalkitusvaikutusta. Kemira-Biotiitti sisältää 5 $\%$ kaliumia, 7 \% kalsiumia ja $10 \%$ magnesiumia.

Biotiitin lannoitusvaikutusta on nurmikasveilla tutkittu varsin laajasti (Saarela 1984, 2001, Huhta 1989, Vuorinen 1989, Linna \& Jansson 1994, Seuri ym. 2001), ja uusiakin tutkimuskenttiä on perustettu (Isolahti \& Virkajärvi 2005). Pääsääntöisesti nurmi on pystynyt hyödyntämään biotiitista vapautuvan kaliumin hyvin, mutta maissa, joissa on luontaisesti korkeat kaliumreservit, on vaikutus ollut vaatimaton niin sadoissa kuin maasta mitatuissa kaliumluvuissakin (Saarela 1984, 2001, Huhta 1989, Vuorinen 1989, Linna \& Jansson 1994, Seuri ym. 2001).

Peruna pystyy hyödyntämään suuret määrät kaliumia. Pääosa sadosta kypsytetään karkeilla kivennäismailla, joiden kalium- ja usein myös kalsiumluvut ovat alhaiset (Lemola ym. 2000), eivätkä reservikaliumvaratkaan välttämättä suuret (Saarela \& Mäntylahti 2002). Biotiitin käyttökelpoisuuden selvittämiseksi perunamailla MTT Pohjois-Pohjanmaan tutkimusasema perusti yhteistyössä Kemira GrowHow’n kanssa kenttäkokeen Liminkaan vuonna 2002.

\section{Aineisto ja menetelmät}

Kenttäkoe perustettiin monokulttuurissa olevalle ruokateollisuusperunalohkolle, jonka viljavuusanalyysissä mitatut ravinnepitoisuudet olivat keväällä 2002 ennen biotiitin levittämistä keskimäärin pH 6.0, Ca 650, P 18, K 110 ja Mg 40. Kentän maalaji oli karkea hieta ja hehkutushäviönä mitattu humuspitoisuus oli 3,05 \% eli juuri multavan ja vähämultaisen rajamailta. Lajikkeena kokeessa käytettiin Famboa.

Koe perustettiin osaruutumallisena, sillä kokeen yhtenä tarkoituksena oli myös selvittää Perunan kalsium Y1 -lannoitteen vaikutusta sadon laatuun. Kokeen pääruututasolla olikin kaksi erilaista vuotuislannoitusvaihtoehtoa (Perunan Y1 750 kg/ha, 60-38-143, Mg 15, Ca 8 tai Perunan kalsium Y1 1034 kg/ha, 60-31-155, Mg 0, Ca 83), mutta tässä artikkelissa keskitytään ainoastaan osaruututason tuloksiin.

Kokeen osaruututaso koostui käsittelemättömästä koejäseneestä sekä tavallisesta ja hapolla käsitellystä biotiitista. Rikkihappokäsittelyn tarkoituksena oli parantaa biotiittiin sitoutuneiden ravinteiden liukoisuutta. Kumpaakin biotiittia käytettiin 10 tonnia hehtaarille ja levitys tehtiin käsin ruuduille pintalannoituksena äestyksen ja jyrsinmuokkauksen välissä. Kokeessa on neljä toistoa, eli osaruututason aineisto koostuu kahdeksan ruudun keskimääräisistä havainnoista.

Viljelytoimenpiteet suoritti maanomistaja tyypillisin viljelyrutiinein tutkimusaseman ohjeistuksella. Koekenttä kynnettiin vuosittain ja istutusmuokkaus suoritettiin vaakatasojyrsimellä. Kokeet havainnoitiin ruuduttain virallisen lajikekoeohjeistuksen mukaisesti (http://www.mtt.fi/tutkimus/alueellinen_tutkimus/ lajikekokeet.html). Tämän lisäksi sadosta analysoitiin K-, Ca- ja Mg-pitoisuudet. Viljavuusanalyysit otettiin vuosittain keväällä ennen istutusta ja syksyllä korjuun jälkeen joka ruudulta.

Varsinainen ruutukoe toteutettiin kasvukausina 2002-03. Kokeen seurantaa jatkettiin maaanalyysejä ottamalla, mutta yksi näytteenottokerta jäi väliin (syksy 2004). Täten artikkelissa keskitytään pääosin maa-analyyseihin. Toisaalta painopiste on tavanomaisessa biotiitissa, koska se on kaupallinen tuote toisin kuin happokäsitelty rinnakkaistuotteensa.

Aineisto analysoitiin tilastollisesti kahtena rinnakkaisena lohkottain satunnaistettuna kokeena. Tilastoajot suoritettiin SASin mixed-proseduurilla. Toistomittausten kovarianssirakenteena oli AR(1).

\section{Tulokset ja tulosten tarkastelu Sato ja sadon kehittyminen}

Sato oli hyvä vuonna 2002 (keskimäärin 44,1 t/ha) ja välttävä vuonna 2003 (32,9 t/ha). Eri koejäsenten välillä ei sadon määrissä ollut eroa. Happokäsitelty biotiitti heikensi hieman kasvuston alkukehitystä ja suurensi mukulakokoa $(\mathrm{p}<0,05)$, johtuen ilmeisesti käsitellyn biotiitin maata happamoittavasta ja maan suolaväkevyyttä nostavasta vaikutuksesta $(\mathrm{p}<0,05)$. Perunakasvusto kuitenkin myös hyötyi happokäsitellystä biotiitista, sillä sadon tärkkelyspitoisuudet olivat käsitellyllä biotiitilla keskimäärin korkeimmat $(\mathrm{p}<0,05)$. Vaikutus oli todennäköisesti seurausta käsitellyn biotiitin magnesiumlannoitusvaikutuksesta (Kuva 4), sillä koekenttä oli magnesiumpitoisuudeltaan viljavuusluokassa huono.

Sadon ravinnepitoisuudet olivat happokäsitellyssä biotiitissa muita korkeammat kalsiumilla ja 
vuonna 2003 kontrollia paremmat muissakin ravinteissa $(\mathrm{p}<0,05)$. Biotiitin ja kontrollin välillä ei ollut sadon ravinnepitoisuuksissa oleellista eroa kumpanakaan vuonna.

Satotuloksiin on kuitenkin suhtauduttava varauksellisesti, sillä kasvustossa oli kumpanakin vuonna suhteellisen paljon tyvimätää (Erwinia carotovora subsp. atroseptica) ja vuonna 2003 erittäin voimakas seittisaastunta (Rhizoctonia solani). Tyvimätää oli biotiittiruuduissa enemmän kuin muissa ruuduissa. Tautipaine oli niin suuri (tyvimätää koejäsenissä keskimäärin 2 - 7 \% ja perunaseittiä vuonna 2003 jopa 25 30 \%), että sillä on todennäköisesti ollut vaikutusta kaikkiin sadosta mitattuihin tunnuslukuihin.

\section{Muutokset maassa: pH}

Maan pH laski ensimmäisenä kasvukautena rajusti happokäsittelyllä biotiitilla verrattuna muihin koejäseniin(p<0,01, Kuva 1). Muutos oli yhteydessä maan suolaväkevyyttä osoittavan johtoluvun nousuun. Maan johtoluku oli happokäsitellyllä biotiitilla ensimmäisen kasvukauden syksyllä 7,3 kun se kontrollilla ja biotiitilla oli 2,5 (p<0,05). Ensimmäisen kasvukauden jälkeen maan pH pysyi happokäsitellyllä biotiitilla kontrollin tasolla, mutta johtoluku oli vielä kasvukaudella 2003 lähes 2,5 yksikköä kontrollia ja biotiittia korkeammalla.

Myös kontrollissa kahtena ensimmäisenä kasvukautena havaittu $\mathrm{pH}-$ luvun lasku $(\mathrm{p}<0,05)$ on merkki maan johtoluvun ja suolaväkevyyden noususta kahden keskimääräisesti hyvin kuivan vuoden takia. Vasta kevään 2004 kovat sateet huuhtoivat maan niin, että pH palasi normaalille tasolleen.

Tavallisella biotiitilla sen sijaan oli hienoinen kalkitusvaikutus, mutta sen vaikutus oli kokonaisuudessaan vaatimaton. Biotiitin ansiosta maan $\mathrm{pH}$ nousi käsittelemättömään kontrolliin verrattuna noin 0,1 pH-yksikköä vuodessa kahden vuoden aikana. Ero on tilastollisestikin merkitsevä vain suuntaa-antavasti. Syksystä 2003 kevääseen 2005 ero pysyi stabiilina $(\mathrm{p}<0,10)$, syksyllä 2005 ero pieneni hieman.

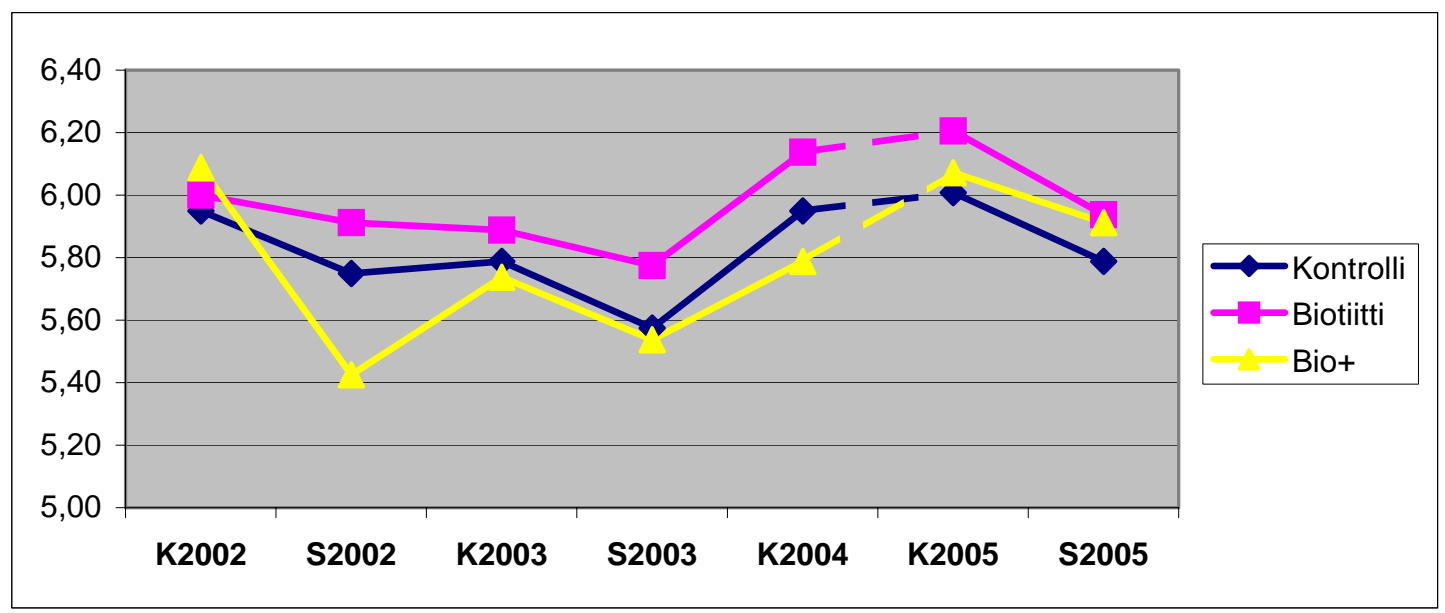

Kuva 1. pH:n muutos maassa kokeen aikana (K=kevät, S=syksy) viljavuusnäytteiden perusteella eri käsittelyissä

\section{Kalsium}

Biotiitit nostivat tehokkaasti maan kalsiumpitoisuuksia ( $<<0,001$, Kuva 2). Tavanomainen biotiitti nosti ensimmäisenä kasvukautena maan kalsiumpitoisuutta noin 140 yksikköä, mutta toisena kasvukautena vaikutus oli pienempi kuin happokäsitellyllä biotiitilla. Tavanomaisen biotiitin kalsiumvaikutus oli tilastollisesti merkitsevä kontrolliin verrattuna vuoden 2005 kevääseen asti $(\mathrm{p}<0,05)$ ja vielä viimeisissä syysnäytteissäkin maan kalsiumpitoisuus oli noin $30 \mathrm{mg} / \mathrm{l}$ korkeammalla kuin kontrollissa. Happokäsitellyn biotiitin kalsiumvaikutus oli tilastollisesti merkitsevä syksyyn 2003 asti, jonka jälkeen vaikutus alkoi vähentyä.

Kalsiumin kokonaisvapautuminen biotiiteista oli huomattavan suurta, sillä erityisesti kasvukausien välisenä aikana kalsiumpitoisuudet ovat laskeneet selvästi $(\mathrm{p}<0,05)$ johtuen ilmeisesti karkean maan huonosta pidätyskyvystä ja huuhtoutumisesta (Kuva 2). Ensimmäisen syksyn korkeat kalsiumpitoisuudet saattavat olla jossain määrin hieman harhaisia, sillä pintalannoitus yhdistettynä tiettyihin viljelytoimenpiteisiin, kuten penkin multaukseen, voi korostaa lannoitteen ravinnemääriä. 


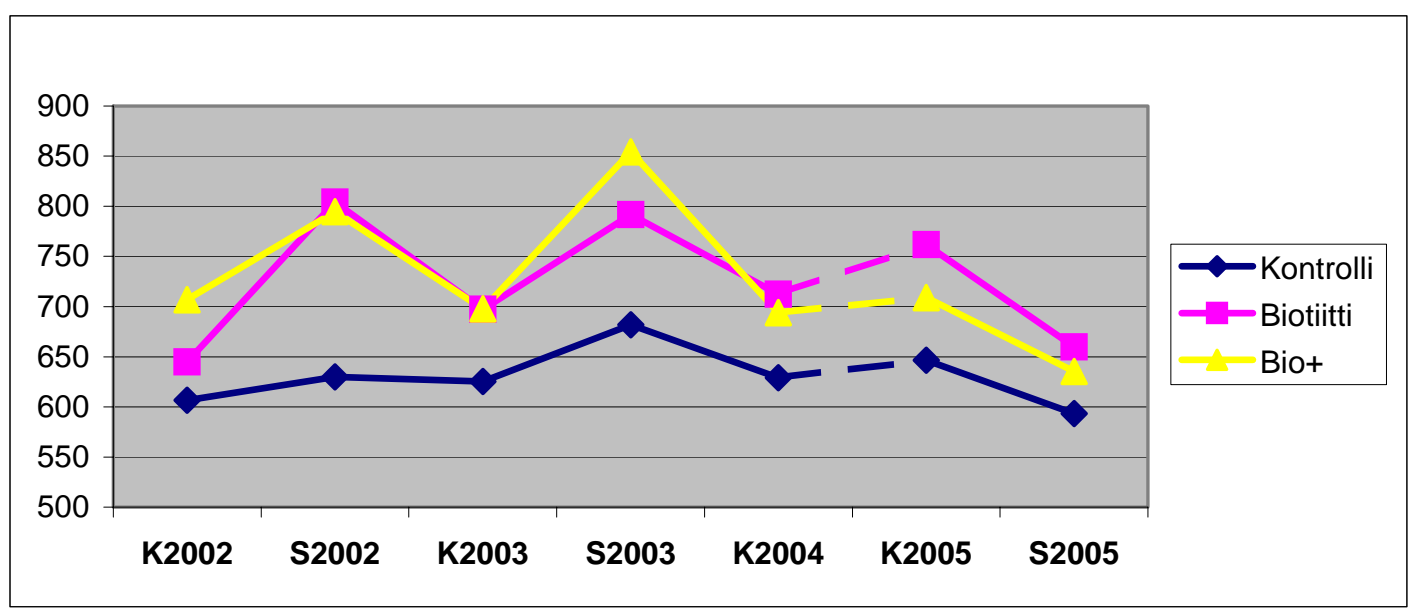

Kuva 2. Viljavuusanalyysin mukaiset maan Ca-luvut (mg/l) eri käsittelyissä kokeen aikana (K=kevät, S=syksy)

\section{Kalium}

Biotiitit lisäävät myös maan kaliumpitoisuuksia ( $<<0,05$, Kuva 3). Happokäsitelty biotiitti nosti maan kaliumpitoisuuksia heti ensimmäisestä vuodesta alkaen $(p<0,05)$, kun tavanomaisella biotiitilla maan kaliumpitoisuuksien nousu alkoi vasta toisesta kasvukaudesta $(\mathrm{p}<0,05)$. Toisena kasvukautena kummankin biotiitin kaliumvaikutus oli maassa yhtä suuri (24 mg/l) ja se erosi tilastollisesti merkitsevästi kontrollista $(p<0,05)$. Syksystä 2003 asti happokäsitellyn biotiitin kaliumlannoitusvaikutus alkoi ehtyä, kun se vielä tavanomaisella biotiitilla oli nousussa kasvukaudelle 2004 tullessa. Syksyyn 2005 mennessä happokäsitellyn biotiitin kaliumvaikutusta ei enää ollut, ja se oli vähäinen myös tavanomaisella biotiitillakin (Kuva 3).

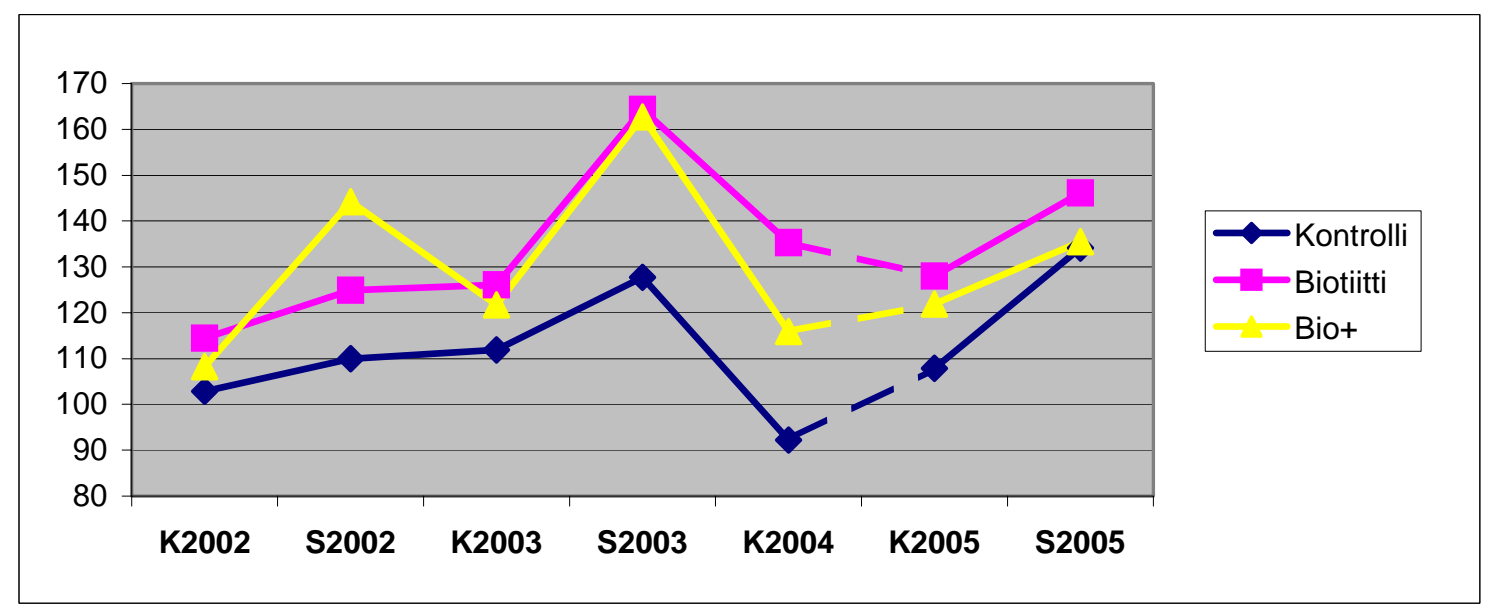

Kuva 3. Viljavuusanalyysin mukaiset maan K-luvut (mg/l) eri käsittelyissä kokeen aikana (K=kevät, S=syksy)

\section{Magnesium}

Eri käsittelyiden vaikutus maan ravinnepitoisuuksiin oli suurin magnesiumilla (Kuva 4). Biotiitin happokäsittely vapautti kahden ensimmäisen vuoden aikana huomattavat määrät biotiittiin sitoutuneesta magnesiumista maaperään $(\mathrm{p}<0,001)$, kun taas tavanomaisen biotiitin magnesium osoittautui niukkaliukoiseksi. Maan magnesiumluvut nousivat vain muutamia yksiköitä vuodessa, vaikka lisätty ravinnemäärä oli tavanomaisella biotiitillakin 1000 kg/ha (Kuva 4). Tavanomaisella biotiitilla oli tilastollisesti merkitsevä vaikutus maan Mg-lukuihin vain syksyllä $2003(\mathrm{p}<0,05)$. Happokäsitellyn biotiitin vaikutus alkoi heikentyä kasvukaudelta 2004 eteenpäin, mutta tilastollisesti merkitsevä se oli vielä keväällä 2005. 


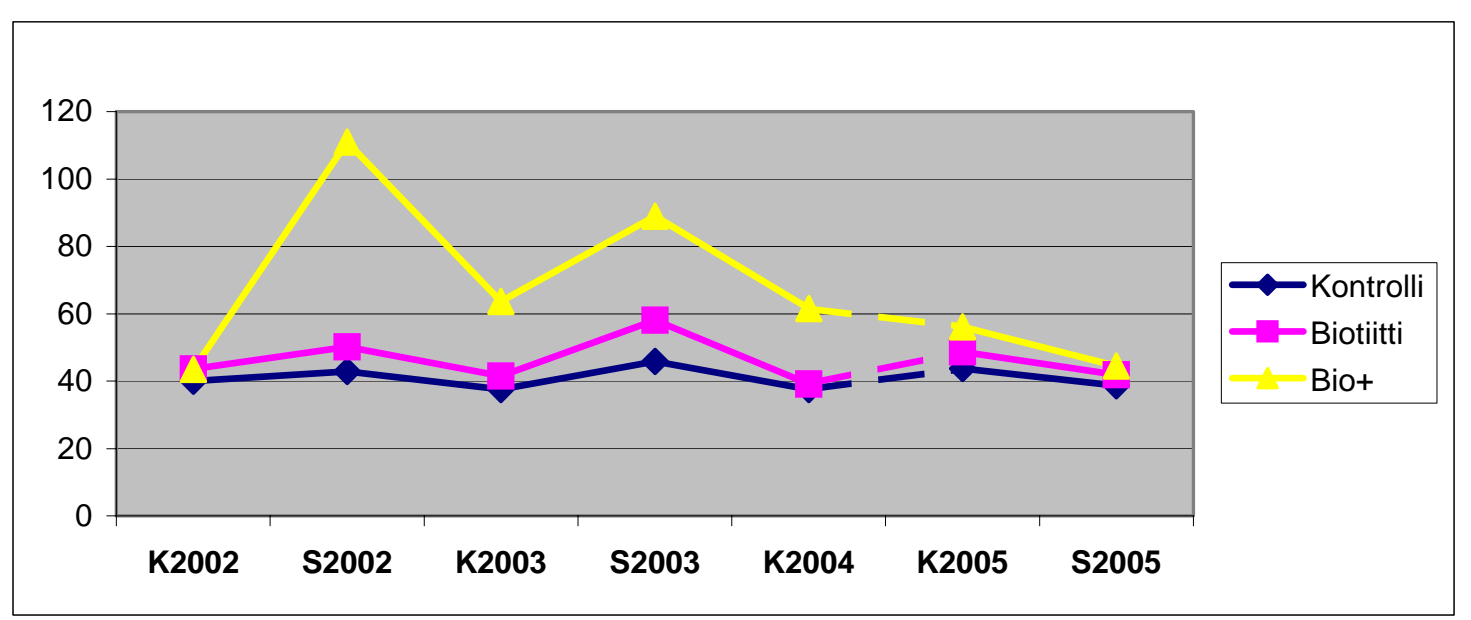

Kuva 4. Mg-luvun (mg/l) muutos maassa kokeen aikana (K=kevät, S=syksy) eri käsittelyissä

\section{Johtopäätökset}

Biotiitti on käyttökelpoinen maanparannusaine erityisesti silloin kun on tarve sekä maan kalsium- että kaliumpitoisuuden nostoon. Pelkkänä maan kalsium- tai kaliumpitoisuuden nostajana biotiitti voi olla kallis, sillä kalkkien ja kuonien Ca-pitoisuudet ovat biotiittia korkeampia ja kaliumin määrää on suhteellisen helppo säätää lannoituksen avulla. Biotiitin käyttökelpoisuutta ruoka- ja siemenperunan tuotannossa parantaa biotiitin vähäinen pH-vaikutus. Samoin vahvuutena on biotiitin kyky parantaa maan pidätyskykyä, sillä perunaa viljellään yleisesti karkeilla mailla. Kalkitusaineeksi tai magnesiumlannoitukseen ei biotiitti ole kilpailukykyinen.

Maan kalsiumia biotiitti nosti tehokkaasti ja maan kaliumia viiveellä. Kaliumin hidasvaikutteisuus saattaa olla ongelmallinen ominaisuus viljeltävän kasvin kaliumlannoitustarvetta etukäteen arvioitaessa. Hidasvaikutteisuuden kääntöpuoli on, että kalium pysyy pitkään huuhtoutumiselta suojattuna. Tämä on selitettävissä sillä, että kiillemineraalien tapaan biotiitin kalium sijaitsee suojassa ns. hilaväleissä (Hartikainen 1992). Tässä koesarjassa kaliumin kokonaisvapautuminen näytti olevan joitain aikaisempia kokeita (Linna \& Jansson 1994, Saarela 2001) hieman vähäisempää. Tuloksista ei ole selvitettävissä paljonko kaliumia vapautui vuoden 2004 aikana. Siihen asti biotiitin kaliumvaikutus oli lisääntynyt, mutta siltä vuodelta syysnäytettä ei ole. On täysin mahdollista, että erittäin märkä kasvukausi 2004 edesauttoi biotiitin ravinteiden vapautumista ja sen jälkeistä mahdollista huuhtoutumista. Voimakkaasta uuttumisesta ja ravinteiden huuhtoutumisesta löytyy todisteita tarkasteltaessa vuosien 2004 - 2005 maa-analyysituloksia muista MTT:n Pohjois-Pohjanmaan tutkimusaseman maanparannusaineiden vaikutuksia selvittäneistä koesarjoista (julkaisematon tieto).

Toisaalta tavanomaisen biotiitin kalsiumvaikutus ylsi vielä märän vuoden 2004 yli. Kalsiumvaikutus koesarjassa olikin selvä, ja mm. aikaisempia koesarjoja jonkin verran suurempi (Saarela 2001). Kalsiumvaikutus oli huomattavasti selkeämpi kuin $\mathrm{pH}$-vaikutus, vaikka Kemira-Biotiitin kalsium on suurimmaksi osaksi maata neutraloivaa kalsiittia. Vaatimaton $\mathrm{pH}$-vaikutus on kuitenkin linjassa aikaisempien tutkimusten kanssa, ja vaikuttaa siltä, että biotiitilla on itsessään maan $\mathrm{pH}$ :ta puskuroivia ominaisuuksia (Linna \& Jansson 1984, Saarela 2001). Puolen viljavuusluokan nousu (+0,2 pH-yksikköä) kymmenellä tonnilla biotiittia vastaa kyseisellä maalajilla reilun tonnin kalsiittikalkitusta (www.farmit.net --> kalkitussimulaattori). Saarelan (2001) astiakokeessa vaikutus oli sama. Vähäinen pH-vaikutus on perunamaalla kuitenkin positiivinen ominaisuus, sillä tavallinen perunarupi (Streptomyces scabies) voi hyötyä pH:n noususta ja aiheuttaa sato ja laatutappioita (Pietilä 1993).

Huolimatta siitä, että biotiitti sisältää ravinteista eniten magnesiumia (10 \%), on tämä magnesium erittäin niukkaliukoista. Maa-analyysien perusteella laskettu magnesiumin vapautuminen kevääseen 2004 mennessä oli noin $30 \mathrm{~kg} / \mathrm{ha}$, mikä on vain $3 \%$ biotiitin mukana lisätystä magnesiummäärästä. Tähän samaan magnesiumin liukoisuuteen pääsi myös Saarela (2001) astiakokeessaan. Peruna tarvitsee runsaan magnesiumlannoituksen (Jokinen 1976), mutta runsaan lannoituksen seurauksena maan ravinnepitoisuudet saattavat vääristyä, ja monien perunamaiden Ca/Mg-suhde onkin lähellä viittä, kun optimi olisi noin 10 (Lemola ym. 2000). Biotiitin ravinteet vapautuvat suurin piirtein optimisuhteessa eikä sen käyttö olennaisesti vaikuta maan $\mathrm{Ca} / \mathrm{Mg}$-suhteeseen. Siitä syystä se on käyttökelpoinen myös magnesiumrikkailla mailla.

Biotiitin happokäsittely toimi odotetulla tavalla. Se tehosti biotiitin ravinnevaikutusta siten, että 
biotiitin magnesiumvarat vapautuivat ja kalium- ja kalsiumvaikutus aikaistui. Kaliumissa tai kalsiumissa ei määrällistä vaikutusta näyttäisi olleen, vaan kummatkin biotiitit vapauttivat ravinteita yhtä paljon. Happokäsittelyn heikkous oli sen maata happamoittava ja maan suolaväkevyyttä nostava vaikutus ensimmäisinä vuosina.

\section{Kirjallisuus}

Hartikainen, H. 1992. Maaperä. Teoksessa: Maa, viljely ja ympäristö. WSOY. s. 8-89

Huhta, H. 1989. Kokemuksia biotiitista suonurmen kaliumlannoitteena. Koetoiminta ja käytäntö 46, 19.12.1989 Isolahti, M. \& Virkajärvi, P. 2005. Muokattu biotiitti nurmen perustamisen yhteydessä. Teoksessa: Lannoitus- ja kasvinsuojelukokeiden tuloksia 2004. MTT/Alueellinen tutkimus \& Kemira GrowHow Oyj. s. 55-63

Jokinen, R. 1976. Perunan magnesium- ja mangaanilannoitus. Koetoiminta ja käytäntö 33, 11: 43,44

Lemola, R., Ojanen, H., Hannukkala, A., Siimes, K. \& Yli-Halla, M. 2000. Siemen-, tärkkelys- ja lastuperunan viljelyn erityispiirteitä Suomessa. Maatalouden tutkimuskeskuksen julkaisuja, sarja A 88. $42 \mathrm{~s}$.

Linna, P. \& Jansson, H. 1994. Biotiitti nurmen kaliumlannoitteena. Maatalouden tutkimuskeskus, tiedote 14. $13 \mathrm{~s}$. Pietilä, L. 1993. Perunarupi. Teoksessa: Perunan kasvinsuojelu. Tieto tuottamaan 66: 46-49

Saarela, I. 1984. Kelpaako kiille kaliumlannoitteeksi? Koetoiminta ja käytäntö 41, 25.9.1984.

Saarela, I. 2001. Siilinjärven biotiitti maanparannusaineena. Tutkimusraportti. MTT/MKF. 5 s.

Saarela, I. \& Mäntylahti, V. 2002. Kiillepitoisten karkeiden maiden kaliumin vapautuminen kasveille. Teoksessa: Maa, josta elämme, II Maaperätieteiden päivien laajennetut abstraktit. Pro Terra 15, 140-142

Seuri, P., Nykänen, A., \& Huhta, H. 2000. Siilinjärven apatiittipöly ja muut hidasliukoiset fosfori- ja kaliumlannoitteet luomuviljelyssä. Tuloksia koesarjasta vuosilta 1990-1995. Maatalouden tutkimuskeskuksen julkaisuja, sarja A 54. $26 \mathrm{~s}$.

Vuorinen, M. 1989. Kiille ja kuonat edullisia turvemaalla. Koetoiminta ja käytäntö 46, 18.4.1989 